\title{
MITTEILUNGEN DER GESELLSCHAFT FÜR INFORMATIK / 219. FOLGE
}

Gesellschaft für Informatik e.V. (GI), Wissenschaftszentrum, Ahrstraße 45, 53175 Bonn, Tel.: 0228/302-145, Fax 0228/302-167, e-mail: gs@gi.de, Server: http://www.gi.de

Geschäftsführung: Dr. Peter Federer, e-mail: peter.federer@gi.de, Tel.: -145

Stellvertreterin der Geschäftsführung: Cornelia Winter, e-mail: cornelia.winter@gi.de, Tel.: -147

Stellvertreter des Geschäftsführers: Alexander Rabe, e-mail: alexander.rabe@gi.de

Sekretariat: Monika Schulte, e-mail: monika.schulte@gi.de, Tel.: -145

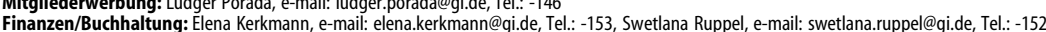

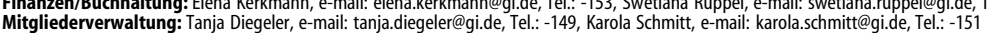

ITK: Christopher Schiller, e-mail: christopher.schiller@gi.de, Tel. - -156

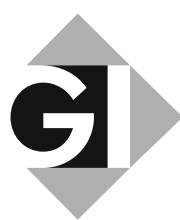

\section{GI-Repräsentanz in Berlin-Mitte eingeweiht (3.12.2012)}

Mit knapp 200 Gästen hat die Gesellschaft für Informatik e.V. (GI) ihr neues Hauptstadtbüro am 29. November 2012 der Öffentlichkeit vorgestellt. Eröffnet wurde die Feier mit Grußworten von GI-Präsident Oliver Günther und Ministerialdirektor Wolf-Dieter Lukas aus dem Bundesministerium für Bildung und Forschung.

„Es ist gut, dass die GI nun in Berlin ist. In der GI ist das unabhängige Fachwissen vorhanden, das wir auch in der Politik brauchen", so Ministerialdirigent Lukas. „Wir freuen uns, mit unser neuen Repräsentanz in Berlin näher am politischen Geschehen zu sein“, sagte GI-Präsident Günther. „Bereits in den ersten Monaten konnten wir unsere Kontakte zu Ministerien und Wirtschaftsverbänden intensivieren und hoffen, die Informatik und die GI so stärker ins Blickfeld der in Politik und Wirtschaft Verantwortlichen zu rücken."

Im Anschluss diskutierten Fachleute aus Wirtschaft, Politik und Forschung über das Thema „IT und Informatik - Vom Jobkiller zum Jobmotor“. „Die Diskussion hat gezeigt, dass Informatik ein Innovations- und Jobmotor schlechthin ist“, so Günther. „,Wir wollen deswegen gemeinsam daran arbeiten, dass sie die Förderung und
Wertschätzung seitens Politik und Öffentlichkeit erfährt, die ihr gebührt“. An der Einweihung nahmen Vertreter der Bundesregierung, der Ministerien, des Bundestages sowie von Verbänden und zahlreichen Unternehmen teil. (Gesellschaft für Informatik e.V. (GI), Hauptstadtbüro, Alexander Rabe, Anna-Louisa-Karsch-Straße 2, 10178 Berlin)

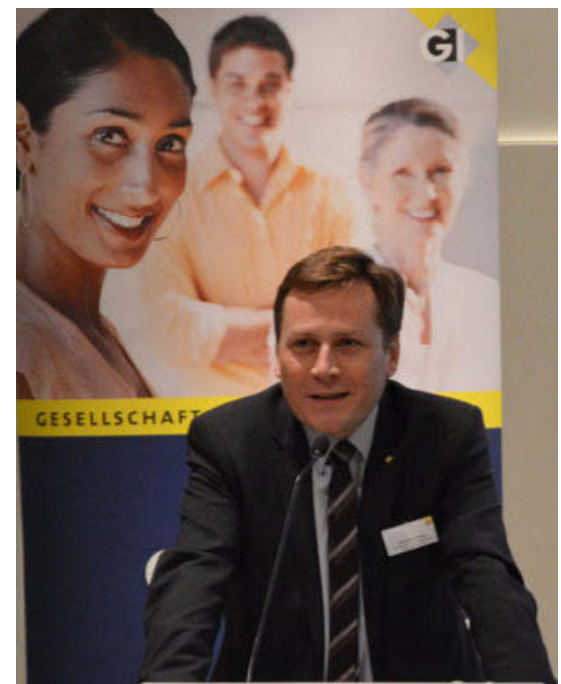

GI-Präsident Günther eröffnet das Berliner Büro

\section{Wahl zum GI-Präsidium}

Am 7. Dezember 2012 fand die Auszählung der Präsidiumswahl statt. Für die Amtszeit 2013-2015 wurden folgende Personen gewählt: Prof. Dr. Wolfgang Karl (1586 Stimmen), Kerstin Lenk (1479 Stimmen) und Prof. Dr. Gudrun Schiedermeier (1409 Stim- men). An der Wahl nahmen insgesamt 2713 Mitglieder teil, davon 2671 elektronisch und 42 per Briefwahl. Wir wünschen den neuen Präsidiumsmitgliedern eine glückliche Hand und viel Freude bei ihrer Arbeit in der und für die GI.

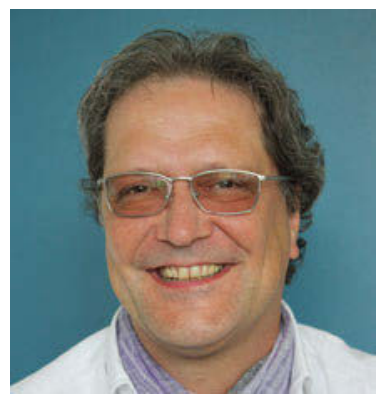

Prof. Dr. Wolfgang Karl

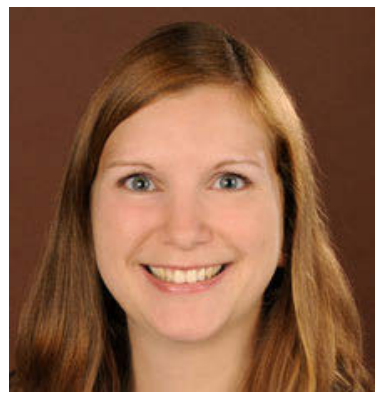

Kerstin Lenk

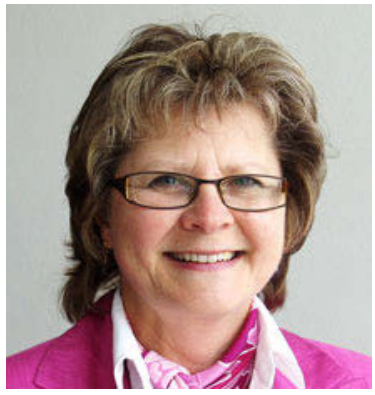

Prof. Dr. Gudrun Schiedermeier 